\title{
BRANDED CONTENT ANTES DEL BRANDED CONTENT: LA MODELACIÓN CULTURAL PROPAGANDÍSTICA COMO FORMA DE PROPAGANDA ENCUBIERTA
}

\author{
Antonio Pineda Cachero \\ (Universidad de Sevilla) \\ apc@us.es
}

\begin{abstract}
Resumen: En este artículo se propone el concepto de "modelación cultural propagandística", como una forma particular de propaganda encubierta en la cual la instancia de poder propagada y su ideología no son identificables explícitamente. Se trata de una comunicación indirecta que utiliza discursos, formatos y contenidos comunicativos que a priori no se considerarían propagandísticos. La modelación cultural propagandística implica una voluntad deliberada de incidir en y dar forma a la cultura, modelarla, de manera que aporte beneficios para el poder.
\end{abstract}

Palabras clave: Tipos de propaganda, propaganda cultural, propaganda encubierta, semiótica de la propaganda, branded content.

Abstract: This paper proposes the concept of "propagandistic cultural moulding", as a particular type of covert propaganda. In this propaganda type, the institution propagated (as well as its ideology) are not explicitly identifiable. It is an indirect kind of communication which employs communicative discourses, formats and contents that would not be regarded a priori "propagandistic". Propagandistic cultural moulding implies a deliberate will to influence and shape culture, mould it, in order to obtain gains for power institutions.

Keywords: Propaganda typology, cultural propaganda, covert propaganda, propaganda semiotics, branded content.

\section{INTRODUCCIÓN. PROPIEDADES DEFINITORIAS DEL OBJETO DE ESTUDIO}

$\mathrm{E}$ n este artículo se propone el concepto de "modelación cultural propagandística" como un tipo específico de propaganda encubierta que reviste un gran interés desde el punto de vista semiótico, y que se adelanta históricamente a fenómenos publicitarios como el branded content, además de superarlo en sutileza ${ }^{1}$. Entenderemos por modelación cultural propagandística (en adelante, MCP):

\footnotetext{
${ }^{1}$ Quiero expresar mi agradecimiento a Jesús Jiménez Varea, profesor del Departamento de Comunicación Audiovisual y Publicidad y Literatura de la Universidad de Sevilla por las sugerencias y comentarios realizados acerca de este trabajo.
} 

propagandística como forma de propaganda encubierta

(a) Un fenómeno propagandístico y, por consiguiente, intencional (Pineda Cachero, 2006). Es decir, es un tipo de influencia comunicativa que persigue deliberadamente efectos favorables a instancias de poder organizadas.

(b) Un tipo de propaganda encubierta, que no se afirma como una comunicación interesada. Aunque propaga ideas favorables al poder, no menciona de manera directa al elemento propagado ni a su ideología.

(c) Un fenómeno comunicativo cuyo objetivo particular es la influencia sobre la cultura. Con ese fin, suele emplear para la difusión ideológica medios y formatos de comunicación que no son considerados a priori como habituales para la acción propagandística.

Es evidente que, al cumplir estas condiciones simultáneamente, las operaciones propagandísticas clasificables como MCP suponen un fenómeno muy restringido $y$, hasta cierto punto, difícil de llevar a cabo. Pero también es un tipo (o subtipo) de propaganda muy interesante desde el punto de vista semiótico, dado el grado de sutileza con el que los contenidos adquieren una connotación propagandística en virtud de una intención deliberada, pero oculta. La "propaganda" (entendiendo por tal el uso habitual, "normal" del concepto) está guiada por una intención deliberada y consciente, e identifica con claridad a la instancia de poder que pretende beneficiarse con el mensaje; la "modelación cultural propagandística" es una forma de propaganda que, aunque parte de una intención de poder deliberada y consciente, opera de forma indirecta, sin revelar el elemento que propaga. La modelación cultural puede servir como contexto pre-persuasivo, como caldo de cultivo previo a la propaganda explícita. La MCP crearía una sensibilidad previa hacia ciertos temas: anatematizaría unos y glorificaría otros, pero sin referencia explícita a una instancia de poder. Su objetivo es crear un determinado ambiente cultural, con predisposiciones favorables del receptor hacia ciertas cuestiones, o desfavorables hacia otras cuestiones.

Es importante destacar que la MCP se produce y difunde primordialmente mediante discursos de tipo institucional, cultural o de entretenimiento que no se suelen considerar a priori propagandísticos, como sí se hace con el discurso de un líder político en época electoral o con los panfletos de la "guerra psicológica" ( $p s y c h o l o g i c a l$ warfare). Ahora bien, que una propaganda emplee medios y formatos artísticos o de entretenimiento no significa que esa propaganda sea MCP. De hecho, la utilización de todo tipo de medios y formatos de comunicación es una constante a través de la historia de la propaganda (Pizarroso Quintero, 1993). Por consiguiente, es necesario señalar que el carácter "descubierto" o "encubierto" en la comunicación es independiente de la utilización de medios y formatos que a priori no se consideran propagandísticos. Es decir, el mero hecho de utilizar programas de entretenimiento $u$ obras artísticas en la propaganda no implica que esta última sea "encubierta". No toda propaganda cultural es por definición MCP. Por ejemplo, el género del comic-book de superhéroes en Estados Unidos se puso al servicio de fines propagandísticos durante la Segunda Guerra Mundial, pero lo hizo al descubierto, atacando a Hitler o Hirohito, fomentando el patriotismo 
estadounidense, o enviando superhéroes al frente (Jiménez Varea, 2004: 158163). La MCP, por el contrario, rehúye esta aproximación directa.

En el nombre dado al concepto que nos ocupa (modelación cultural propagandística) se ha incluido el adjetivo cultural por dos razones. En primer lugar, al entender que denomina un fenómeno cuya circulación comunicativa se produce preferentemente a través de formatos y medios de la cultura de élite, la cultura de masas, la cultura popular y, por extensión, la vida cotidiana. La modelación propagandística es "cultural" porque aparece en medios de comunicación donde el contenido propagandístico se filtra con otras dimensiones de la cultura. Como veremos, incluso las pinturas del expresionismo abstracto pueden ser utilizadas para la MCP. En segundo lugar, la modelación propagandística es "cultural" porque, para funcionar, precisa de cierta circulación y absorción en el contexto sociocultural que la rodea. No está anclada en un elemento propagado identificable (como sí ocurre con la propaganda "normal"), sino que adquiere significación en un contexto pragmático más amplio.

La idea de modelación cultural propagandística tiene un sentido privilegiado en la época contemporánea. La existencia de una cultura de masas con fines aparentemente lúdicos y el diseño consciente de campañas de propaganda utilizando medios indirectos, son factores que generan un vínculo especialmente sólido entre la MCP y las condiciones de la comunicación de masas contemporánea. No obstante, teóricamente sería posible hablar de MCP en épocas anteriores al desarrollo de los medios de comunicación de masas y la propaganda "científica". Cumplir los requisitos de una MCP no precisa la disponibilidad de una tecnología de la comunicación avanzada.

\section{MODELACIÓN CULTURAL PROPAGANDÍSTICA Y OTROS CONCEPTOS AFINES}

La modelación cultural propagandística es un tipo concreto de propaganda. Para conceptualizarla, hay que partir de la distinción que establece Kimball Young (citado en Herreros Arconada, 1989: 124) entre propaganda manifiesta (por ejemplo, la propaganda electoral) y propaganda encubierta (por ejemplo, la propaganda que adopta las formas del periodismo). La MCP, específicamente, sería un sub-tipo de la "propaganda encubierta" (covert propaganda).

Un concepto que sería prácticamente idéntico al de MCP es el de subpropaganda. Ésta se entiende como actividades -de relaciones públicas, generalmente- que facilitan el aumento de emisores de propaganda: becas, cursos, etc. Acuñado por Doob, el término subpropaganda se refiere a la construcción de estructuras mentales para la introducción de nuevas doctrinas. Trabaja, pues, a largo plazo. L. John Martin, de la U.S. Information Agency (citado en Jowett y O'Donnell, 1986: 20), denomina a este tipo de propaganda facilitative communication, que se basa en mantener contactos para el día en que sirvan a fines propagandísticos. Según Jowett y O’Donnell, este tipo de propaganda emplea 


\section{0 \\ Branded Content antes del Branded Content: la modelación cultural propagandística como forma de propaganda encubierta}

sobre todo -y además de situaciones que crean actitudes positivas (fiestas, viajes, turismo, comercio, inversiones, etc.)- medios de tipo cultural:

Facilitative communication most frequently takes the form of radio newscasts, press releases, books, pamphlets, periodicals, cultural programs, exhibits, films, seminars, language classes, reference services, and personal social contacts. These are all arranged in an effort to create a friendly atmosphere toward those who may be needed later on (1986: 20).

En estos términos, la subpropaganda equivaldría a una descripción factual de la MCP. Salvo por un pequeño detalle: la naturaleza encubierta de esta última. Crear "estructuras mentales" y "una atmósfera amistosa" puede hacerse de manera explícita o implícita; lo interesante de la MCP es que lo hace de manera implícita ${ }^{2}$. En cierto modo, la MCP es propaganda encubierta y subpropaganda al mismo tiempo, un producto híbrido de ambas.

Además, la subpropaganda parece más un proceso psicológico que una cuestión de identificación (o no) del Emisor: "This is when the propagandist's task is to spread an unfamiliar doctrine, for which a considerable period of time is needed to build a frame of mind in the audience toward acceptance of the doctrine", señalan Jowett y O’Donnell (1986: 20) sobre la subpropaganda. "In order to gain the target audience's favour, various stimuli are used to arouse the attention of the audience and the related encoders and agents who mediate communication". A diferencia de esto, la MCP no tiene necesariamente que basarse en la propagación de una nueva "doctrina".

Por otro lado, la modelación cultural propagandística podría asimilarse parcialmente al concepto de propaganda negra expuesto por Pizarroso Quintero (1993: 29): "[...] aquella en la que la fuente emisora está deliberadamente falsificada, independientemente de la falsedad o veracidad del mensaje". En todo caso, matizaremos que en la MCP "la fuente emisora" no necesariamente es "falsificada"; simplemente, se oculta al Receptor.

\footnotetext{
2Jacques Ellul (1973: 30) distingue entre "pre-propaganda (o sub-propaganda)" y "active propaganda". La pre-(o sub-)propaganda tiene como objetivo esencial "to prepare man for a particular action, to make him sensitive to some influence, to get him into condition for the time when he will effectively, and without delay or hesitation, participate in an action [...]. It proceeds by psychological manipulations, by character modifications, by the creation of feelings or stereotypes useful when the time comes. It must be continuous, slow, imperceptible" (Ellul, 1973: 31). Con esa apelación a lo "imperceptible" podría pensarse que la sub-propaganda, en el sentido que le da Ellul, correspondería a la MCP; ahora bien, como el mismo Ellul explica: "Political education, in Lenin and Mao's sense, corresponds exactly to our idea of sub-propaganda, or basic propaganda, as Goebbels would say [...]. To make this clear, we will use the classic terms of propaganda and agitation, taken in a new sense. Propaganda is the elucidation of the Marxist-Leninist doctrine (and corresponds to pre-propaganda); agitation's goal is to make individuals act hic et nunc, as a function of their political education and also in terms of this "education" (which corresponds to what we call propaganda)" (1973: 32, nota 5). La propaganda leninista, en un sentido general, no era necesariamente indirecta ni secreta; por consiguiente, parece que la subpropaganda tampoco es un fenómeno necesariamente encubierto.
} 
También podría trazarse cierto paralelismo entre las categorías de "propaganda política" y "propaganda de integración" (observadas por Jacques Ellul -1973-) y, respectivamente, los conceptos de propaganda (por su carácter directo) y modelación cultural propagandística (por su carácter indirecto), siempre que se considere la "propaganda de integración" elluliana como un proceso deliberado. No obstante, y en general, las categorías de Ellul no son lo suficientemente explicativas, pues atienden más al cómo, a la técnica y al contexto, que a la intención del Emisor y su actividad deliberada y consciente. Otro concepto de Ellul que tendría puntos de contacto con la idea de la MCP es el de "propaganda sociológica"; una categoría de propaganda con carácter indirecto:

[...] it is based on a general climate, an atmosphere that influences people imperceptibly without having the appearance of propaganda; [...] Sociological propaganda produces a progressive adaptation to a certain order of things, a certain concept of human relations, which unconsciously molds individuals and makes them conform to society (Ellul, 1973: 64).

La idea de que la propaganda sociológica "moldea" al individuo, y que se basa en un "clima" o una "atmósfera", sería interesante para describir la operativa de la MCP; el problema es que la propaganda sociológica no se plantea como una actividad intencional: "Sociological propaganda springs up spontaneously; it is not the result of deliberate propaganda action" (Ellul, 1973: 64). En este punto discrepamos de Ellul, pues, según nuestro marco teórico, la comunicación propagandística es por definición una actividad intencional (Pineda Cachero, 2006). Y lo mismo se aplicaría a la MCP en tanto que tipo de propaganda.

Más allá de los tipos de propaganda, y aunque no existe una correspondencia exacta, podría realizarse un paralelismo entre propaganda y MCP, por un lado, y las técnicas de lobbying directo e indirecto, por otro. Como la propaganda, el lobbying directo deja bien clara la identidad del grupo de presión o de interés en función del cual se realiza la acción de lobby; como la MCP, el lobbying indirecto se basa en influir sobre la opinión pública, en crear un clima de opinión (para que ulteriormente esta misma opinión pública influya sobre la Administración y, así, se cumplan los objetivos del lobbista y del grupo de presión que le contrata). La modelación cultural propagandística opera con métodos aún más sutiles que los de esta forma de lobbying, pero el carácter indirecto es análogo.

\section{TIPOS DE MODELACIÓN CULTURAL PROPAGANDÍSTICA}

La influencia indirecta sobre la cultura con fines de poder admite dos formas básicas:

1) Modelación cultural propagandística estratégica. Opera a largo plazo, y su labor consiste en insertar contenidos funcionales para la ideología del poder. 


\section{Branded Content antes del Branded Content: la modelación cultural propagandística como forma de propaganda encubierta}

2) Modelación cultural propagandística táctica. Opera a corto plazo, y su labor consiste en insertar contenidos funcionales para la satisfacción de los intereses inmediatos del poder.

Un ejemplo de MCP estratégica podría ser la conformación por parte del régimen nazi de los espacios radiofónicos de entretenimiento como una exaltación nacionalista y un refuerzo de tesis propagandísticas, aumentando por ejemplo la difusión de música clásica de compositores alemanes como medio indirecto de propaganda (cfr. Faus Belau, 1995: 47). En cuanto a casos de MCP táctica, la propaganda de tipo bélico puede tender, debido a sus necesidades, a intentar ejercer una influencia inmediata sobre el clima cultural. Un ejemplo de MCP táctica bélica serían los esfuerzos de la Office of War Information (OWI) estadounidense durante la Segunda Guerra Mundial. El Radio Program Bureau de la OWI, pensando en evitar el rechazo de la propaganda gubernamental, intentó influir indirectamente en la programación. Un caso fue, en 1942, la diseminación radiofónica del mensaje "DoN'T TRAVEL AT XMAS.", con el fin de minimizar los viajes innecesarios de los civiles en pro de los viajes de los militares. "The OWI recommended playing on the consciences of the civilian whose selfish pleasure trip might make a soldier miss his Christmas visit home" (Sproule, 2005: 189).

Aunque existe evidencia sobre MCP de tipo táctico, es lógico pensar que la forma óptima de MCP es la de tipo estratégico, pues es la que mejor se adapta a la idea de moldear soterradamente una cultura. La premura implícita en la MCP táctica (ganar unas elecciones, resistir en una guerra, etc.) conlleva que los valores que se pretenden propagar apenas cuentan con tiempo para asentarse en la cultura. Probablemente, trabajar a largo plazo es el precio a pagar por intentar transformar la esfera de las ideas. La MCP táctica, por el contrario, perseguiría efectos más limitados e inmediatos, como fomentar el miedo a lo que se presenta como una amenaza próxima.

Desde otro criterio taxonómico, y en tanto que tipo de propaganda, a la MCP pueden aplicarse los mismos criterios de carácter primario o secundario que a la propaganda en general (Pineda Cachero, 2005: 567-569). En consecuencia, podría hablarse de una MCP primaria, emitida directamente por la instancia de poder, y de una MCP secundaria, emitida por agentes propagandistas secundarios -con vínculos más o menos formales con el poder- que intentan modelar conscientemente la cultura de forma que beneficie a una instancia de poder determinada. Es decir, la MCP puede ser llevada a cabo tanto por los beneficiarios directos del poder como por sus propagandistas secundarios.

En cuanto a un criterio taxonómico político, podría hablarse de MCP en estados democráticos y MCP en estados no democráticos. Como se verá en el apartado siguiente, existe evidencia empírica de MCP en ambos contextos políticos. 


\section{LA MODELACIÓN CULTURAL PROPAGANDÍSTICA EN EL TOTALITARIS- MO: EL CASO DE LA ALEMANIA NAZI}

En el caso de los estados totalitarios, las ideas de Goebbels sobre el cine serían un ejemplo que corresponde al concepto de MCP: el cine de entretenimiento, si bien empapado de ideología, no debe presentar contenidos propagandísticos directos; el cine documental sí es apología directa de la ideología oficial -piénsese en los trabajos de Leni Riefensthal-. La aproximación indirecta al cine pudo radicar en que "unlike Hitler, Goebbels believed that propaganda was most effective when it was insidious, when its message was concealed within the framework of popular entertainment" (Welch, 1995: 48). Rafael de España observa que uno de los principios del cine de Goebbels radica en que "[a]unque las películas transcurran en otros países u otras épocas, los argumentos deben adaptarse a la mentalidad de la sociedad en que se producen" (2002: 39).

En esta línea, pueden recordarse películas alemanas filmadas bajo el Tercer Reich como Jud Süss (El judío Süss), de Veit Harlan, que según Rafael de España es "el mayor éxito del ciclo antisemita" (2002: 42). Ahora bien, El judío Süss está ambientada en el siglo XVIII, con lo que la referencia al poder nazi no sería directa. Pero sí se mantiene la intención de propagar los elementos antisemitas presentes en la cosmovisión nazi, dado que su argumento narra la historia de un judío "intrigante" que permite que el país "sea literalmente saqueado por sus correligionarios", además de mostrar "la violación de la virginal hija de un concejal" a manos judías (De España, 2002: 42). El propio Goebbels dijo de Jud Süss que era un "éxito enorme, una obra genial. Exactamente el tipo de película antisemita que queríamos." (citado en Moeller, 2000: 99. Traducción propia.). Otro ejemplo de mensaje de MCP cinematográfica en el nazismo es la película Kolberg (también de Veit Harlan), estrenada en enero de 1945. Según Goebbels, en un mensaje telegrafiado al comandante de la fortaleza La Rochelle:

La película es un canto artístico al valor y a la resistencia de aquellos que están dispuestos a ofrecer a su patria y a su pueblo los mayores sacrificios. Se estrenará con la mayor dignidad como símbolo de la estrecha unión del frente y de la población civil en la lucha y en reconocimiento de las virtudes ejemplares representadas por los hombres que aparecen en la pantalla. Le deseo que el filme le sirva a usted y a sus valientes soldados como un documento de la entereza inquebrantable de un pueblo, que en estos días de lucha total se encuentra unido al frente batallador en la voluntad de imitar a sus grandes antepasados de su gloriosa historia. ¡Heil nuestro Führer! (citado en Schulze Schneider, 2004: 172-173).

Este objetivo de comunicación se ajusta a las necesidades del poder nazi en el contexto histórico de la película, pues, cuando ésta se estrenó, Berlín ya estaba semidestruido. No obstante, el pequeño detalle de que Kolberg está ambientada en 1806 (cuando Napoleón entra en Alemania, el ejército alemán sufre derrotas y la fortaleza prusiana de Kolberg resiste) permite entender la película como una versión a corto plazo de los mismos objetivos que guiaban El judío Süss: dar forma a la opinión pública de manera favorable a los intereses del poder nazi. De 


\section{Branded Content antes del Branded Content: la modelación cultural propagandística como forma de propaganda encubierta}

hecho, según Goebbels, Kolberg formaba parte de la "guerra psicológica", y su objetivo era "mostrar con el ejemplo de esa ciudad que da el título a la película, que una política llevada a cabo conjuntamente por soldados en el frente y por la población civil en casa es capaz de vencer a cualquier enemigo" (citado en Schulze Schneider, 2004: 169). Cuando tras la caída del Tercer Reich la película fue distribuida en Argentina y en Suiza, el periódico Neue Zürcher Zeitung alentó a los suizos a rebelarse contra la "infiltración" de "pensamientos pertenecientes a la ideología nazi" (citado en Schulze Schneider, 2004: 174). Una acertada descripción de la idea de la MCP.

El procedimiento nazi de desplazar el contexto histórico en su propaganda también se aplicó a la propaganda sobre Austria, donde "historical serials and plays also played down the differences between the Austrians and the Germans. Two radio plays-Alfons von Czibulka's The Reich Saves Vienna and Reimesch's The Town in Arms-dealt, in ridiculously imprecise terms, with the subject of the siege of Vienna by the Turks in 1683" (Zeman, 1964: 129). La atención a este tipo de formatos, más una aproximación indirecta, parece una constante. Como señala Zeman en Nazi Propaganda (1964: 114):

Plays and serials-many of them on famous men from the age of discoveries, colonization, or of the wars of liberation-were quite popular with the planners of programmes in Berlin. A special stress was laid on the pioneering work done by the Germans; the achievements of the National Socialist regime were also extolled. But an attempt was made to exclude the more obvious forms of propaganda; a good deal of care was devoted to the 'German Study Circle', a series of programmes on a variety of academic subjects (El subrayado es nuestro).

En general, y más allá de los contenidos de entretenimiento, hay indicios de que los esfuerzos de propaganda cultural indirecta fueron una característica del nazismo. Por ejemplo, a los Centros de Intercambio Intelectual Germano-Españoles de Madrid y Barcelona les fue impreso un "sesgo político-propagandístico" tras la toma del poder por los nazis en 1933 (De la Hera Martínez, 2002: 441). Pues bien, según observaba el director del Centro de Intercambio Intelectual Germano-Español de Madrid, Alfons Adams, a mediados de la década de 1930, una de las características de la táctica de la política cultural alemana en España era "la influencia a través de la palabra y de la escritura"; un aspecto englobado en lo que Adams llamaba "el camino indirecto": "tan equivocado es el método directo de la explicación política en España, como acertado y necesario es el de la influencia indirecta a través de la palabra y la escritura" (citado en De la Hera Martínez, 2002: 296).

\section{LA MODELACIÓN CULTURAL PROPAGANDÍSTICA EN LA DEMOCRACIA: EL CASO DE ESTADOS UNIDOS}

Como ya se ha sugerido, la MCP tiene más sentido en las democracias, dado que se trata de sistemas políticos donde el poder tiende a ser controlado 
públicamente $\mathrm{y}$, por ello, precisa en ocasiones de medios sutiles para la infiltración ideológica. La propaganda de Estados Unidos en el siglo XX ofrece casos interesantes de MCP.

Un ejemplo al respecto es el ofrecido por Frances Stonor Saunders (2001) en su excelente investigación La CIA y la guerra fría cultural. Se trata de un ejemplo que evidencia que el concepto de la MCP no es solamente aplicable a la cultura de masas, sino que también puede utilizarse para el estudio de la propaganda de élite:

Durante los momentos culminantes de la guerra fría, el Gobierno de Estados Unidos invirtió enormes recursos en un programa secreto de propaganda cultural en Europa occidental. Un rasgo fundamental de este programa era que no se supiese de su existencia. Fue llevado a cabo con gran secreto por la organización de espionaje de Estados Unidos, la Agencia Central de Inteligencia. El acto central de esta campaña encubierta fue el Congreso por la Libertad Cultural, organizado por el agente de la CIA, Michael Josselson, entre 1950 y 1967. Sus logros fueron considerables y su propia duración no fue el menor de ellos. En su momento álgido, el Congreso por la Libertad Cultural tuvo oficinas en 35 países, contó con docenas de personas contratadas, publicó artículos en más de veinte revistas de prestigio, organizó exposiciones de arte, contaba con su propio servicio de noticias y de artículos de opinión, organizó conferencias internacionales del más alto nivel y recompensó a los músicos y a otros artistas con premios y actuaciones públicas. Su misión consistía en apartar sutilmente a la intelectualidad de Europa occidental de su prolongada fascinación por el marxismo y el comunismo, a favor de una forma de ver el mundo más de acuerdo con «el concepto americano» (Stonor Saunders, 2001: 13).

Este caso supone un ejemplo modélico para ilustrar el concepto de modelación cultural propagandística: intención propagandística deliberada pero oculta, uso de medios culturales para la diseminación ideológica, y sutileza a la hora de proceder a dicha diseminación. Este último punto es importante, y en el caso de esta campaña cultural estadounidense alcanzó cotas que creemos difíciles de superar, como evidencia el uso que se hizo de la estética del expresionismo abstracto. Para la "elite cultural estadounidense [...]" el expresionismo abstracto expresaba "una ideología específicamente anticomunista, la ideología de la libertad, de la libre empresa. Al no ser figurativo ni poder expresarse políticamente, era la verdadera antítesis del realismo socialista" (Stonor Saunders, 2001: 353). En consecuencia:

Las relaciones entre la política cultural de la guerra fría y el éxito del expresionismo abstracto no es algo casual... Fueron conscientemente creadas en aquella época, por parte de algunas de las figuras más influyentes que controlaban las políticas de los museos y que abogaban por una táctica ilustrada en la guerra fría, para seducir a los intelectuales europeos (Eva Cockroft, citada en Stonor Saunders, 2001: 366).

El caso de la instrumentalización del expresionismo abstracto por el poder estadounidense es un ejemplo paradigmático del concepto de MCP. Su naturaleza 


\section{Branded Content antes del Branded Content: la modelación cultural propagandística como forma de propaganda encubierta}

propagandística es evidenciada por los nexos formales con el poder; en este caso, los vínculos entre el personal directivo del Museum of Modern Art de Nueva York y la CIA (cfr. Clark, 2000: 130). Según escribe Toby Clark (2000: 8-9) en Arte y Propaganda en el siglo XX:

Mirándolo retrospectivamente, el destino del expresionismo abstracto apenas puede sorprendernos: durante la Guerra Fría el programa de propaganda del Estado le sacó hasta la última gota. Las numerosas exposiciones internacionales que a finales de los años cuarenta y cincuenta exportaban este arte estaban coordinadas por el Museum of Modern Art de Nueva York (MOMA), e iban acompañadas de las manifestaciones de sus conservadores en las que la retórica nacionalista contraponía la «marca de libertad» de la pintura americana al reglamentado arte kitsch del comunismo soviético.

Por otro lado, se trata de un caso de propaganda encubierta (no se afirma como una comunicación interesada), ya que algunas de las exposiciones habían sido financiadas en secreto por la CIA (cfr. Clark, 2000: 9), y, aunque propaga ideas favorables al poder (ideas funcionales contextualmente para Estados Unidos en la Guerra Fría), no menciona de manera directa al elemento que se propaga ni a su ideología; más aún, el expresionismo abstracto se defendía como un "arte puro y libre" (Clark, 2000: 8). Finalmente, destaca el uso de un medio artístico, del que a priori no se sospecha que sea un vehículo propagandístico.

El caso de la United States Information Agency (USIA) también es interesante para contemplar las posibilidades de la propaganda cultural encubierta e indirecta. La intención propagandística de esta agencia, creada en 1953, es clara: según un memorando presidencial de 1963, la USIA debía "contribuir a la consecución de los objetivos de los Estados Unidos... influyendo sobre las actitudes públicas de otras naciones" (citado en Schiller, 1987: 63). Un aspecto importante de la USIA desde el punto de vista de la MCP es que no siempre se identifica como emisor de la información que produce. La USIA distribuyó programas, guiones y producciones por todo el mundo (cfr. Schiller, 1976: 79-80), en el contexto de lo que puede entenderse como un proceso consciente de penetración político-cultural. En palabras de un ex-oficial de la USIA, los productos televisivos estadounidenses "están dando la tónica de la programación de televisión en el mundo entero más o menos de la misma manera que lo hizo Hollywood con respecto a las películas hace cuarenta años". Este oficial también afirmó en 1967 que "la pantalla de televisión se está convirtiendo en el principal ejemplo del modelo norteamericano para millones de personas en el extranjero" (Wilson P. Dizard, citado en Schiller, 1976: 84).

La figura de Disney resulta asimismo potencialmente interesante para la ilustración de la MCP estadounidense. Disney fue el principal emisario cultural de la oficina del Coordinador de Asuntos Interamericanos (CAIA). La CAIA (Vidal González, 2006: 112-115) había sido creada por Franklin Delano Roosevelt bajo el principio fundamental de mostrar la verdad sobre el American way. Para John Hay Whitney, director de la Sección Cinematográfica del Coordinador de Asuntos 
Interamericanos y ayudante de Nelson Rockefeller ${ }^{3}$, el papel de Disney como productor de entretenimiento para niños "le situaba en una posición fuera de sospecha en lo que a vinculación con el gobierno se refiere. La oficina de Rockefeller envió a Disney y a parte de su equipo de viaje por varios puntos de América Latina con la idea de que su presencia se ganara no sólo al público en general, sino también a los oficiales públicos" (Vidal González, 2006: 115-116). Quizá en eso radique la explicación de que, entre las películas de Disney para Latinoamérica, se realizasen películas aparentemente de entretenimiento, pero consideradas como propaganda indirecta (Vidal González, 2006: 119).

\section{MODELACIÓN CULTURAL PROPAGANDÍSTICA: UN EJERCICIO DE SUTI- LEZA SEMIÓTICA}

La diferencia entre la propaganda, por un lado, y fenómenos específicos como la MCP, por otro, implica diferencias relativas a la semiótica del mensaje propagandístico. La propaganda "normal" suele apuntar directamente al beneficiario de la comunicación, vinculando con claridad lo que en términos técnicos denominamos el propagado (las intenciones del poder tras un mensaje propagandístico) y el propagandema (la representación semántica de los intereses del poder en el mensaje propagandístico) (Pineda Cachero, 2006). La MCP funciona de manera más sutil, provocando, no una vinculación directa entre el propagado y el propagandema, sino una diseminación abstracta de significados que pueden redundar positivamente para el poder. $Y$ ahí es donde radican tanto la sutileza como la dificultad conceptual de fenómenos como la MCP, pues la conexión entre el propagado " $P$ " y el propagandema " $X$ " no se realiza explícitamente en el mensaje (como sería el caso de la propaganda "normal"). En la MCP se espera que el propagandema " $X$ " connotado en un mensaje sea asociado por el receptor al propagado más allá de lo que se diga literalmente en el mensaje, de la misma manera que los propagandistas nazis podían esperar que las connotaciones antisemitas de una película ambientada en el siglo XVIII fueran transferidas por el espectador a la Alemania de su tiempo. Considérese el siguiente caso, también del cine nazi: como comenta Rafael de España sobre el film de 1933 Fugitivos (Flüchtlinge, de Gustav Ucicky), la acción

se sitúa en Manchuria en 1928: un excombatiente alemán de la Gran Guerra que, molesto por ver a su país en manos del parlamentarismo judeosocialista, ha decidido servir como soldado de fortuna en China, se convierte en el caudillo providencial que ayudará a un grupo de compatriotas que huyen de la Rusia comunista. Enmascarado bajo una apariencia de film de aventuras, la trama deja claro al espectador que el pueblo alemán necesita confiar ciegamente en un führer que le lleve a la salvación (De España, 2002: 41).

\footnotetext{
${ }^{3}$ Según Pizarroso Quintero, "el 16 de agosto de 1940 Nelson Rockefeller fue nombrado «Coordinator of Inter-American Affairs», para contrarrestar la gran influencia de la propaganda nazi y fascista en Iberoamérica" (1993: 402).
} 


\section{Branded Content antes del Branded Content: la modelación cultural propagandística como forma de propaganda encubierta}

Este ejemplo es útil para entender la lógica semiótica de la MCP: el propagandema del "liderazgo" no se conecta con el propagado hitleriano, sino que se disemina mediante una narración ambientada en otra época. Para cumplir los objetivos del poder, es el receptor quien debe conectar el propagado y el propagandema, de la misma forma que en el caso del uso ideológico del expresionismo abstracto por parte de Estados Unidos, los intelectuales objetivo de la campaña eran quienes debían relacionar el propagandema de la "libertad" con los fines del poder estadounidense. Es evidente, en este contexto, que casos como la MCP incrementan la importancia de los aspectos pragmáticos del mensaje propagandístico.

Los niveles de sutileza que puede alcanzar la MCP revisten gran interés desde el punto de vista de la semiótica de la comunicación social. Un ejemplo de sutileza semiótica extrema sería el fomento de películas de horror para crear una atmósfera de miedo político. En febrero de 1995, Diario 16 Andalucía informó que, desde el Ministerio de la Presidencia, el Gobierno español aconsejaba a cadenas televisivas públicas y privadas que programasen películas de terror, "según han confirmado a DIARIO 16 diversos directivos de A-3 TV, T-5 y TVE" (D16 / MADRID, 1995: 60). Según uno de estos directivos,

parece ser que se trata de sembrar subliminalmente el miedo entre la ciudadanía, de la misma forma que filtran supuestos malestares en las Fuerzas Armadas o el miedo a la derecha. Y, de paso, para fabricar una "realidad" a base de vampiros, psicópatas y muertos vivientes aún más inquietante de la que vive España. Es surrealista, de risa, pero comprensible si se tiene en cuenta la importancia que el Gobierno y el PSOE conceden a la televisión como instrumento de propaganda (citado en Ibidem).

\section{PAUTAS TEÓRICAS Y METODOLÓGICAS PARA EL ANÁLISIS DE LA MO- DELACIÓN CULTURAL PROPAGANDÍSTICA}

La variedad de formatos y contenidos explotables como MCP, unida al carácter no-explícito de esta última, podría llevar a una postura teórica monista sobre la propaganda (Pineda Cachero, 2007), en la cual toda creación cultural se viera como propaganda, como connotación de valores potencialmente útiles para el poder. Pero eso no es así necesariamente.

Considérese el caso del lenguaje. Más allá de que un determinado idioma pueda usarse como herramienta de penetración cultural y política (De Oyarzábal, 2001: 88), podría pensarse en una utilización propagandística indirecta del lenguaje, lo cual es bastante similar a la idea de MCP. Según Victor Klemperer, el medio de propaganda más potente del hitlerismo era el lenguaje: a diferencia de los medios de comunicación que podían captarse "mediante el pensamiento o el sentimiento conscientes", como los discursos o las octavillas, el nazismo "se introducía más bien en la carne y en la sangre de las masas a través de palabras aisladas, de expresiones, de formas sintácticas que imponía repitiéndolas millones de veces y que eran adoptadas de forma mecánica e inconsciente" 
(Klemperer, 2002: 31). Esta operativa recuerda bastante a una acción de propaganda cultural indirecta; sin embargo, ¿equivaldría todo uso del lenguaje a una acción de MCP?

Para empezar ni siquiera un uso abiertamente propagandístico del lenguaje equivaldría a una MCP. Para que esta última se dé, la instancia de poder correspondiente debería, por ejemplo, utilizar palabras cuyo significado no se relacione explícitamente con la ideología propagada; es decir, palabras cuyas connotaciones sean funcionales sólo de manera indirecta, intentando procurar una absorción cultural de contenidos semánticos favorables al poder. Pero lo más importante es que, desde un punto de vista analítico, y siguiendo con el ejemplo del lenguaje, la intencionalidad debe ser el criterio que evite el monismo propagandístico: el lenguaje no es algo per se propagandístico, pero puede ser empleado propagandísticamente en la modelación cultural, como ocurre con ejemplos totalitarios como la manipulación nazi del lenguaje. De hecho, si tenemos también en cuenta el ejemplo mencionado anteriormente sobre las películas de terror, queda reforzada la hipótesis -más general- de que el principio explicativo del fenómeno propagandístico radica en una intención determinada (Pineda Cachero, 2006), hasta el punto de que los contenidos adquieren un carácter secundario frente a la intención comunicativa. Una película usada en la MCP puede tener contenidos ideológicos aunque esté ambientada en otra época, pero en casos como el del lenguaje o el de las películas de terror ni siquiera tienen por qué existir contenidos ideológicos en el mensaje: la intención de poder es lo que puede transformar las palabras o el terror en una acción propagandística ${ }^{4}$.

Así, en la MCP el estudio de la intención del Emisor prima sobre el del contenido del Mensaje: existe una intención propagandística generadora $\left(I_{p}\right)$ que pretende ocultar su naturaleza propagandística tras contenidos no-propagandísticos $\left(C_{\neg p}\right)$. Esa $I_{p}$ pretende ocultarse tras la intención no-propagandística $\left(I_{\neg p}\right)$ que se les presupone inicialmente a los $C_{\neg p}$ (por ejemplo, una intención comercial que se presupone a un contenido aparentemente de entretenimiento). La clave, en todo caso, es que bajo estos últimos $C_{7 p}$ existen otros elementos de contenido puramente propagandístico $\left(C_{p}\right)$, más sutiles. $Y$ en esa sutileza radica la esencia de la MCP. Intentemos comprender el proceso mediante una suerte de fórmula, donde la MCP equivaldría a

$$
I_{p}\left(C_{\neg p}\right)=C_{p}
$$

Hemos extrapolado a la MCP la idea matemática de la función al considerar que puede ilustrar la mecánica de este tipo de propaganda encubierta: la intención propagandística operaría como una "función" donde los contenidos nopropagandísticos $\left(\mathrm{C}_{7 \mathrm{p}}\right)$ de un mensaje -lúdicos, informativos, etc.-, que serían el "dominio de la función", adquieren el "valor" propagandístico p mediante la "función ideológica" $I_{p}\left(C_{\neg p}\right)$, siendo $C_{p}$ el "recorrido" o conjunto de "valores" que

\footnotetext{
${ }^{4}$ Para la noción de "ideología" que manejamos en el contexto de nuestro marco teórico sobre la propaganda, véase Pineda Cachero, 2006: 193-220.
} 


\section{Branded Content antes del Branded Content: la modelación cultural propagandística como forma de propaganda encubierta}

toma la función ideológica. Desde este punto de vista, el modo en que los $C_{7 p}$ adquieren valor " $p$ " podría ser un ámbito de estudio para el análisis del funcionamiento de la propaganda en la cultura. ¿En qué medida, por ejemplo, valores de lucha social que podrían ser universales en películas como El acorazado Potemkin (1925), de Eisenstein, adquieren una funcionalidad bolchevique, de forma que el "recorrido" de esos valores de libertad se transforma contextualmente en propaganda del poder?

Si consideramos el caso de la instrumentalización del expresionismo abstracto por parte de la $\mathrm{CIA}$, nos percataremos de que, en sus manifestaciones más sutiles, lo que hace la MCP es imputar a unos $C_{\text {pp }}$ (pinturas abstractas) un valor propagandístico "p" mediante una intención de poder (combatir a la estética soviética), de manera que esos $C_{\urcorner p}$ funcionan pragmáticamente como $C_{p}$ (ideología anticomunista de la libertad). Formalmente:

$$
\mathrm{I}_{\mathrm{p}}\left(\mathrm{C}_{\neg p}\right)=\mathrm{C}_{\mathrm{p}}
$$

I "anti-URSS" ( $C_{\neg p}$ "expresionismo abstracto") = $\mathrm{C}_{\mathrm{p}}$ "anticomunismo"

En resumen, y puesto que la $I_{p}$ actúa como principio generador del mensaje,

$$
\text { I "anti-URSS" } \rightarrow \text { C }_{p} \text { "anticomunismo" }
$$

Metodológicamente, para analizar un mensaje o conjunto de mensajes como producto de MCP es preciso:

(a) Investigación empírica sobre las condiciones de emisión del mensaje, pues es necesario demostrar con datos los vínculos del emisor propagandista con instancias de poder, o bien su intención de trabajar en pro de instancias de poder. Sin este tipo de vínculos con el poder, no puede hablarse de MCP. Podemos pensar en muchos productos del arte y de la cultura de masas cuyos contenidos ideológicos pueden ser funcionales para las necesidades del poder; ahora bien, ¿han sido esos contenidos generados ex profeso para el beneficio de una instancia de poder? Este es el tipo de preguntas que distinguen nuestra postura teórica de aquellas otras que entienden la propaganda como una cuestión de recepción, más que de emisión intencional.

(b) Análisis del contenido ideológico del mensaje. Consistiría en aplicar los conceptos de intención propagandística $\left(\mathrm{I}_{\mathrm{p}}\right)$, contenido no-propagandístico $\left(C_{7 p}\right)$ y contenido propagandístico $\left(C_{p}\right)$, según la fórmula ya vista sobre la $\operatorname{MCP}\left(I_{p}\left(C_{\neg p}\right)=C_{p}\right)$. Dentro de esta aplicación, el análisis de la MCP implica la descripción empírica de:

b.1) Qué intereses y necesidades del poder guían $I_{p}$. En términos técnicos ya citados, cuál es el propagado del mensaje.

b.2) Cuáles son los $C_{\neg p}$, aparentemente neutros y desvinculados de una intención propagandística. Sería el momento de analizar el contenido de entretenimiento, informativo, artístico, etc. 
b.3) Cómo los $C_{\neg p}$ se transforman en $C_{p}$, mediante la función que desempeña la $I_{p}$. Los $C_{p}$ remiten a otro término técnico ya mencionado: el propagandema, la síntesis semántica del mensaje propagandístico. Sería el momento de analizar cuál es el significado (el propagandema) que se pretende vincular indirectamente a una instancia de poder (el propagado).

\section{CONCLUSIONES}

Desde el punto de vista de la investigación teórica sobre el fenómeno propagandístico, el estudio de la MCP gira el punto de atención hacia el polo emisor. Comunicacionalmente, la intención propagandística se revela como un factor fundamental en formas de propaganda encubierta como la MCP, en consonancia con el papel básico y generador que posee el factor intencional en la esencia de la propaganda en general. Es posible que la operativa práctica de la MCP presuponga ciertos efectos (e incluso cierta colaboración pragmática) en el receptor, pero lo cierto es que, desde un punto de vista teórico, la existencia de indicios sobre una intención propagandística deliberada y consciente es fundamental a la hora de distinguir la MCP de conceptos ellulianos tan vaporosos como el de "propaganda sociológica". En esta línea, consideramos que el concepto de modelación cultural propagandística supone una aportación a la tipología de la propaganda, en conexión estrecha con otras clases de propaganda, aunque sin identificarse con ellas.

En el contexto más amplio de las Ciencias de la Información y la Comunicación, y concretamente en cuanto a las relaciones entre la propaganda y la comunicación comercial, la MCP implica históricamente la idea del branded content antes del branded content, el cual podría verse como una evolución muy sofisticada del product placement. Según Thom O'Leary, Director of International Operations en la empresa iTVX: "Product placement is getting much more sophisticated. It's no longer just a box of cereal in the background. It's the car the sitcom character has got to go out and buy because it's cool and it becomes organically woven into the universe of the show." (Thom O'Leary, citado en Blagg y DeVaney, 2005). Este entrelazado orgánico de lo comercial puede, en todo caso, ir más allá del producto y hacerse más inmaterial; así, "el advertainment o branded content es una simbiosis perfecta entre publicidad y entretenimiento que tiene como principal objetivo atraer al público hacia los valores de la marca de forma atractiva y sugerente" (Ramos, 2006: 39). Si la idea del branded content (también llamado advertainment, como se ha visto, o branded entertainment) es integrar los valores de una marca comercial en productos de entretenimiento, la existencia de acciones propagandísticas clasificables como MCP evidencia que la inspiración tras el branded content es, en realidad, una vieja idea de la propaganda encubierta. ¿Qué significan películas nazis como las mencionadas anteriormente sino la integración de los "valores de marca" nazis en películas de entretenimiento? ¿No podría verse El acorazado Potemkin como un entretejido de valores explotables 


\section{Branded Content antes del Branded Content: la modelación cultural propagandística como forma de propaganda encubierta}

por los bolcheviques, e insertados en una narración ambientada antes de la revolución bolchevique? Una acción de MCP pretende infiltrarse en la cultura, de la misma forma que el branded content más sofisticado persigue infiltrar valores comerciales en productos culturales. Y, de hecho, los niveles de sutileza de la MCP son todavía mayores que los del branded content, pues en el caso de la MCP ni siquiera aparece la "marca" publicitada (en términos propagandísticos, el propagado), como sí suele ocurrir en el advertainment.

En cierto modo, la forma de propaganda formulada en este artículo nos lleva a las relaciones de la propaganda con la Teoría de la Cultura. En el caso de la $\mathrm{MCP}$, la lógica interna de la propaganda implicaría que la cultura dirige al individuo hacia elecciones ideológicas predeterminadas por el poder. En este contexto, es evidente que el diseño o utilización de un producto cultural como instrumento del poder responde a la mentalidad de aquellos "para quienes la cultura es no sólo un instrumento de poder sobre las cosas, sino también, y muy especialmente, de dominio sobre los hombres", como decía Antonio Machado (1986: 23); una mentalidad opuesta al punto de vista cultural de la llustración.

\section{REFERENCIAS BIBLIOGRÁFICAS}

BLAGG, A.; DeVANEY, S.: Advertainment Tonight. The Wave Magazine [en línea]. Vol. 05, Issue 14: July 13 - 26, 2005. [Consulta: 21 julio 2005]. <http://www.thewavemag.com/printarticle.php?articleid $=25358>$

CLARK, T. (2000): Arte y Propaganda en el siglo XX. Traducción: Isabel Balsinde. Tres Cantos (Madrid): Akal.

DE ESPAÑA, R.: Imágenes del nazismo: el cine del Tercer Reich. En CAMARERO, G. (2002): La mirada que habla (cine e ideologías). Tres Cantos (Madrid): Akal, pp. 36-44.

DE LA HERA MARTÍNEZ, J. (2002): La política cultural de Alemania en España en el período de entreguerras. Madrid: Consejo Superior de Investigaciones Científicas.

DE OYARZÁBAL, A.: "La condición lingüística de las relaciones internacionales", Nueva revista de política, cultura y arte, 74, marzo/abril de 2001, pp. 84-88.

D16 / MADRID: "El Gobierno «aconseja» a las cadenas que programen películas de terror", en Diario 16 Andalucía, 24 de febrero de 1995, p. 60.

ELLUL, J. (1973): Propaganda. The Formation of Men's Attitudes. Traducción del francés de Konrad Kellen y Jean Lerner. Nueva York: Vintage Books.

FAUS BELAU, A. (1995): La era audiovisual. Barcelona: Ediciones Internacionales Universitarias.

HERREROS ARCONADA, M. (1989): Teoría y técnica de la propaganda electoral (formas publicitarias). Barcelona: PPU.

JIMÉNEZ VAREA, J.: Historietas de superhéroes y propaganda bélica durante la Segunda Guerra Mundial. En HUICI MÓDENES, A.; PINEDA CACHERO, A. (2004): Propaganda y Comunicación. Sevilla: Comunicación Social Ediciones y Publicaciones, pp. 153-173. 
JOWETT, G. S.; O’DONNELL, V. (1986): Propaganda and Persuasion. Newbury Park/ Londres/Nueva Delhi: Sage Publications.

KLEMPERER, V. (2002): LTI. La lengua del Tercer Reich. Traducción de Adan Kovacsics. Barcelona: Editorial Minúscula.

MACHADO, A. (1986): Juan de Mairena, II. Edición de Antonio Fernández Ferrer. Madrid: Cátedra.

MOELLER, F. (2000): The Film Minister. Translated from the German by Michael Robinson. Stuttgart/London: Menges.

PINEDA CACHERO, A. (2005): Elementos para una teoría comunicacional de la propaganda. Tesis Doctoral dirigida por: Dr. Manuel Ángel Vázquez Medel y Dr. Adrián Huici Módenes. Universidad de Sevilla, Sevilla.

- (2006): Elementos para una teoría comunicacional de la propaganda. Sevilla: Alfar.

- : “ ¿Todo es propaganda? El panpropagandismo o monismo propagandístico como límite superior de la teoría de la propaganda". Comunicación. Revista Internacional de Comunicación Audiovisual, Publicidad y Estudios Culturales N 5, 2007, pp. 415-436.

PIZARROSO QUINTERO, A. (1993): Historia de la propaganda. $2^{a}$ edición, ampliada. Madrid: Eudema.

RAMOS, M.: "Cuando la marca ofrece entretenimiento: aproximación al concepto de advertainment”. Questiones Publicitarias, Volumen I, n 11, 2006, pp. 33-49.

SCHILLER, H. I. (1976): Comunicación de masas e imperialismo yanqui. Traducción de Caroline Phipps. Barcelona: Gustavo Gili.

- (1987): Los manipuladores de cerebros. $2^{\mathrm{a}}$ edición. Traducción: Eduardo Goligorsky. Barcelona: Gedisa.

SCHULZE SCHNEIDER, I.: La propaganda nazi en la Segunda Guerra Mundial. En HUICl, A. (2004): Los heraldos de acero. Sevilla: Comunicación Social Ediciones y Publicaciones, pp. $152-175$.

SPROULE, J. M. (2005): Propaganda and Democracy. Cambridge y New York: Cambridge University Press.

STONOR SAUNDERS, F. (2001): La CIA y la guerra fría cultural. Traducción de Rafael Fontes. Madrid: Debate.

VIDAL GONZÁLEZ, R. (2006): La actividad propagandística de Walt Disney durante la Segunda Guerra Mundial. Salamanca: Publicaciones Universidad Pontificia de Salamanca.

WELCH, D. (1995): The Third Reich. Politics and Propaganda. Londres y Nueva York: Routledge.

ZEMAN, Z. A. B. (1964): Nazi Propaganda. London, New York, Toronto: Oxford University Press / The Wiener Library. 
134 Branded Content antes del Branded Content: la modelación cultural propagandística como forma de propaganda encubierta

\section{Breve semblanza biográfica del autor}

Antonio Pineda Cachero es Doctor por la Universidad de Sevilla y trabaja como docente e investigador en el Departamento de Comunicación Audiovisual y Publicidad y Literatura de la misma Universidad. Entre sus líneas de investigación se encuentran la teoría de la propaganda y la semiótica de la publicidad.

(Recibido el 04-07-2008, aceptado el 14-03-2009) 